\title{
O impacto da preferência pela liquidez na disponibilidade de crédito dos municípios do Espírito Santo
}

\author{
Edson Zambon Monte ${ }^{1}$ \\ Mirian Almeida Viana ${ }^{2}$
}

\begin{abstract}
Resumo: este trabalho teve como objetivo geral identificar quais os impactos da preferência pela liquidez do público (PLP) e dos bancos (PLB) na disponibilidade de crédito nos municípios do Espírito Santo. Adotou-se a técnica econométrica de dados em painel pooled (empilhado). Os resultados obtidos para o período de 2005 a 2010 confirmaram que a PLB e a PLP afetam negativamente a oferta de crédito nos municípios do Espírito Santo, com maior influência da PLB do que da PLP. Além disso, verificou-se que a disponibilidade de crédito é maior nos municípios mais dinâmicos, ou seja, mais desenvolvidos. No mais, há evidências de que a preferência pela liquidez é um importante fator na explicação da tendência à concentração regional do crédito nos municípios capixabas.
\end{abstract}

Palavras-chave: preferência pela liquidez, crédito, Espírito Santo.

Classificação JEL: C23; E51; R11. 


\title{
The impact of the liquidity preference in credit availability of the municipalities of Espírito Santo
}

\begin{abstract}
: the objective of this paper was to estimate the impact of the liquidity preference of public (PLP) and banks (PLB) in credit availability in the municipalities of Espírito Santo. The study was based on the polled panel data technique. According to the results, the PLB and the PLP affects negatively the credit supply in the municipalities of Espírito Santo. The PLB effect was bigger than PLP effects. Moreover, the availability of credit is higher in dynamic cities, i.e., cities more developed. Furthermore, there is evidence that the liquidity preference is an important factor in explaining the tendency to regional concentration of credit in the municipalities of the Espírito Santo.
\end{abstract}

Key-words: liquidity preference; credit; Espírito Santo.

JEL Classification: C23; E51; R11.

\section{Introdução}

A estratégia de atuação dos bancos é definida pela busca contínua de adequação de seus ativos a uma relação entre lucro e liquidez, frente à conjuntura econômica vigente e às expectativas que formam sobre o futuro econômico (Nogueira; Crocco; Figueiredo, 2009). Dentro dos moldes da operação bancária surge uma importante característica de atuação financeira que é a preferência pela liquidez (PL), que se fundamenta na decisão dos agentes em reterem mais ou menos moeda em função das condições em que se encontra o ambiente econômico dado o grau de incerteza.

Assim, ao avaliar o portfólio de um banco, percebe-se que, quando suas expectativas forem mais otimistas quanto ao futuro ou quanto à uma determinada região, os bancos valorizam mais a rentabilidade em troca de liquidez, elevando prazos e submetendo-se a maiores riscos ao aumentar a oferta de crédito regional. Dessa forma, ocorre um crescimento da participação dos ativos de maior risco na composição de sua estrutura ativa, por exemplo, com maior parcela de empréstimos de maior maturidade (Fraga, 2009). Em contrapartida, em momentos de expectativas ruins quanto ao futuro, os bancos irão privilegiar sua liquidez e proteger-se dos riscos financeiros.

As instituições bancárias podem afetar a circulação de moeda na economia de acordo com suas decisões. Os bancos podem preferir realizar compra de 
ativos na circulação financeira, ou seja, títulos públicos, ou então na circulação industrial, financiando os investimentos das empresas. Como agentes especulativos, os bancos obtêm lucros através da diferença entre as taxas de juros pagas a seus ativos e as obrigações que refletem os diferentes prêmios de liquidez associados a cada classe de contrato (Carvalho, 1996).

Embora os bancos tenham uma natureza particular e específica, eles são igualmente empresas inovadoras e dinâmicas em busca da ampliação de seus lucros como qualquer outro agente privado (Freitas, 2009). A sensibilidade dos bancos em relação às demandas de crédito por parte do público não bancário depende das preferências que orientam essas decisões de portfólio em perspectiva de maiores lucros. Portanto, a disponibilidade de crédito seria, nesta lógica, um resultado das escolhas bancárias em relação à alocação de seus recursos (Carvalho, 1996).

Nogueira, Crocco e Figueiredo (2009) enfatizam que os bancos apresentam táticas de atuação diferenciadas para cada região. Para isso, o sistema bancário assumiria a hipótese de que a preferência pela liquidez é distinta no espaço e, através de suas expectativas quanto ao futuro de determinada região, dado seu grau de desenvolvimento, tomaria suas decisões quanto à alocação de recursos.

Segundo Dow e Fuentes (2006), a preferência pela liquidez não afeta apenas o comportamento dos bancos, mas também o comportamento do público. A moeda representa, aos olhos do público, poder de compra, um direito sobre bens e serviços disponíveis ou a serem produzidos. Neste caso, uma maior preferência pela liquidez encoraja o público a adotar portfólios mais líquidos que garantam conversões mais prontamente realizáveis e sem detrimentos.

$\mathrm{O}$ aumento na preferência pela liquidez por agentes regionais em regiões periféricas pode, então, causar um fluxo de recursos financeiros em direção a regiões centrais, o que pode reduzir a disponibilidade local de crédito. A fuga de recursos afeta a disponibilidade de crédito, dependendo do efeito que tais atividades regionais têm sobre a preferência pela liquidez regional dos bancos (Dow; Fuentes, 2006).

Considerando esses aspectos, pode-se dizer que a consolidação do setor bancário no Brasil foi acompanhada por uma concentração regional do crédito nas duas últimas décadas. Conforme Silva (2011) a oferta de crédito do Sistema Financeiro Nacional (SFN) é muito concentrada nas Unidades Federativas mais desenvolvidas. Freitas e Paula (2010) exemplificam a evidência de concentração bancária através do ponto de vista regional, com a relação de crédito estadual entre os diferentes estados brasileiros. Conforme os autores, este comportamento de concentração bancária regional pode ser reflexo da aquisição de bancos, com forte atuação local, por grandes aglomerados bancários sediados na Região Sudeste.

No que se refere ao Espírito Santo, Caçador e Monte (2011) investigaram a 
relação entre financiamento e crescimento econômico nos municípios capixabas. Os resultados demonstraram que as operações de crédito impactam o Produto Interno Bruto (PIB) total dos municípios de forma significativa. Também se verificou a ocorrência de estatísticas significativas para o PIB industrial, PIB agropecuário e para o setor terciário. Quanto à preferência pela liquidez, contudo, não se verificou na literatura econômica regional local análises para o Espírito Santo.

Ainda, Caçador e Monte (2011) descrevem que o Espírito Santo, que representa o,86\% do total das operações de crédito do país, possui características que o distingue dos demais estados brasileiros quanto ao sistema financeiro regional, a saber: a) é uma das poucas Unidades da Federação em que o governo estadual ainda é controlador de um banco estadual, o Banco do Estado do Espírito Santo (Banestes); b) possui um fundo constitucional de financiamento, o Fundo de Recuperação Econômica do Estado do Espírito Santo (Funres); c) possui um banco de desenvolvimento estadual, o Banco de Desenvolvimento do Espírito Santo (BANDES); e, d) o norte do Espírito Santo é integrado à área de abrangência de Superintendência de Desenvolvimento do Nordeste (Sudene).

Nesse contexto, dado que (i) a preferência pela liquidez pode alterar as decisões do público e dos bancos quanto às estratégias de alocação de ativos e passivos; (ii) que o Espírito Santo possui particularidades bancárias em relação à outras Unidades da Federação, como a presença de um Banco de Desenvolvimento; (iii) que não existem estudos que analisam o impacto da preferência pela liquidez do público e dos bancos na oferta de crédito em nível capixaba; e, (iv) que a oferta de crédito tende a impactar significativamente no crescimento de uma região, o objetivo geral deste trabalho foi verificar como a preferência pela liquidez do público e dos bancos afeta a oferta de crédito nos municípios do Espírito Santo. De forma específica, estimou-se regressões complementares a fim de captar os efeitos das variáveis PIB, depósitos à vista, depósitos a prazo e uma dummy regional sobre a oferta de crédito dos municípios capixabas.

\section{Revisão de literatura}

Diversas são as correntes teóricas para a discussão do papel da moeda e dos mercados financeiros na economia regional. Os trabalhos têm sido ampliados e diversificados para investigar como as variáveis financeiras podem ou não influenciar a macroeconomia e qual a relação intrínseca entre moeda e o desenvolvimento regional (Cavalcante; Crocco; Jayme Jr., 2006). Sob esta interpretação serão apresentados os principais resultados teóricos que fundamentam o papel da moeda na economia regional.

A teoria ortodoxa da firma bancária considera que o problema fundamental 
enfrentado pelos bancos consiste na escolha entre um conjunto de ativos rentáveis e com baixa liquidez e um conjunto de ativos com baixa rentabilidade e alta liquidez. Definido por Oreiro (2005), a ortodoxia justifica esse problema pelo fato do volume total de depósitos à vista ser uma variável aleatória, de tal forma que o banco está sujeito ao risco de ocorrência de uma redução súbita e inesperada do volume dos depósitos em consideração. Nesta lógica, o banco está subordinado a manter ativos pouco rentáveis em carteira por precaução, contra a possibilidade de ter que recorrer ao mercado interbancário ou ao redesconto do Banco Central, para obter a liquidez necessária para atender aos saques de seus correntistas.

Para os monetaristas a economia regional lida com uma oferta de moeda horizontal dada uma taxa de juros que, por sua vez, é fixada em mercados nacionais ou internacionais. De acordo com Cavalcante, Crocco e Jayme Jr. (2006) existiria uma livre movimentação de capitais entre as regiões com um caráter indireto de atuação da moeda, que influenciaria na renda regional apenas por meio de seus efeitos na renda nacional ou de outras variáveis reais.

A economia macromonetária também tem dado grandes contribuições para o entendimento do poder da moeda em economias regionais. De acordo com Cavalcante, Crocco e Jayme Jr. (2006), o modelo neoclássico busca desenvolver trabalhos para verificar uma antiga discussão: a neutralidade da moeda. Para Crocco, Cavalcante e Barra (2003) a corrente teórica define a moeda apenas como um meio de troca, não sendo capaz de afetar as variáveis reais da economia. Desta forma, a moeda atuaria na economia como mero intermediário entre as relações financeiras.

Keynes (1936) apresentou em sua obra, Teoria Geral, a abordagem de preferência pela liquidez, contribuindo para a discussão da neutralidade da moeda. Keynes conceitua a moeda como um ativo com atributos particulares: elevado prêmio pela liquidez frente às outras classes de ativos e elasticidade de produção igual à zero, ou inelástica. Esses fatores se dão em decorrência da impossibilidade da classe empresarial em poder aplicar mão de obra em uma produção crescente de moeda à medida que seu preço sobe em termos de unidades de salários e, porque, quando seu valor de troca aumenta, não existe nenhuma tendência para substituí-la por algum outro fator. Tais características fazem com que a moeda satisfaça a preferência pela liquidez dos agentes, pois, em determinadas circunstâncias, estas peculiaridades farão com que a taxa de juros permaneça insensível, particularmente abaixo de certo nível, a um aumento substancial na quantidade de moeda proporcionalmente às outras formas de riquezas.

Para Keynes (1985), os baixos níveis de manutenção da moeda fazem com que o público aumente seu estoque de moeda, pois, desta forma, não se corre o risco de prejuízo como os outros ativos. Logo, em qualquer estado de expectativa, há na mente do público o interesse em conservar dinheiro líquido em quantidade superior a necessária as transações financeiras. O estado de 
confiança, ou seja, o grau de confiança que as instituições de crédito concedem às pessoas que nelas procuram empréstimo, é um dos principais fatores que determinam a disposição de investimentos e as condições de crédito. Portanto, uma queda da confiança pode levar a um violento enfraquecimento do crédito.

Já os pós-keynesianos constituem uma escola de pensamento econômico que busca a construção de uma nova interpretação da economia. Para tanto, introduzem em sua nova análise o tempo e a incerteza, baseando-se em pressupostos keynesianos (Fraga, 2009). Para os pós-Keynesianos a moeda é não exógena, entrando no sistema econômico por intermédio do crédito gerado pelos bancos e induzido pela sua demanda. Assim, como expõe Crocco et al. (2003), o crédito permite determinar o investimento tornando a moeda parte integrante do processo econômico e não neutra.

A possibilidade de que o futuro traga consigo choques imprevisíveis gera um ambiente de incerteza. Este ambiente, por sua vez, faz com que os indivíduos prefiram manter suas escolhas abertas até que o ambiente se torne mais seguro para se tomar decisões. Como a acumulação de riqueza é uma atividade voltada para o futuro, os agentes preferirão, a princípio, manter seus ativos líquidos, porque ninguém sabe como será o futuro (Carvalho, 1996).

A preferência pela liquidez seria o elemento fundamental para determinar a estratégia dos bancos quanto à composição de seus balanços (Oreiro, 2005). Portanto, espelhando-se na abordagem de preferência pela liquidez, os bancos buscam a maximização do lucro, direcionando seus portfólios de acordo com suas expectativas quanto ao futuro. Nos períodos de expectativas boas quanto ao futuro, os bancos buscarão privilegiar a rentabilidade em troca de maior liquidez. Nos momentos de expectativas ruins, a liquidez será preferencial nas decisões bancárias (Fraga, 2009).

Estendendo a análise da corrente teórica pós-keynesiana, é importante ressaltar que a teoria se distingue das demais por abordar tanto o lado da oferta quanto o da demanda no mercado de crédito regional. Crocco, Cavalcante e Barra (2002) descrevem que a oferta e demanda de crédito são interdependentes e afetadas pela preferência pela liquidez, vinculada à expectativa que os agentes formam em um ambiente de incerteza. Em análise de Crocco et al. (2003), do ponto de vista dos bancos, a preferência pela liquidez afetará negativamente a sua disposição a emprestar a uma região caso possuam expectativas pessimistas sobre a mesma. No lado do público, a preferência pela liquidez afetará suas respectivas definições de portfólio. Portanto, quanto maior for à preferência pela liquidez maior às posições em ativos líquidos e menor a disposição de crédito (Dow, 1999).

Com isso, regiões menos desenvolvidas, com bancos em menores estágios de desenvolvimento, têm menor capacidade de criação de crédito, pois estão mais suscetíveis as baixas de poupança e depósitos. Considerando tais aspectos, a incerteza tem um papel fundamental na determinação da preferência pela 
liquidez dos agentes, sendo maior quanto mais remota for à região e quanto mais distante estiver o emprestador do tomador de crédito. A preferência pela liquidez ainda pode ser influenciada pela expectativa regional de crescimento da renda, instabilidade da região e expectativas quanto à direção das políticas monetárias coordenadas pelo Banco Central (Cavalcante; Crocco; Jayme Jr., 2005).

Dessa forma, baixas expectativas em relação à economia regional levam ao aumento da preferência pela liquidez, o que deprime a demanda por fundos, uma vez que investidores se tornam mais precavidos e não querem se endividar. Por outro lado, altas expectativas regionais aumentariam a demanda por crédito, tanto porque os bancos também se tornam mais otimistas e ofertam mais crédito, quanto porque investidores estão mais propensos a tomar recursos (Cavalcante; Crocco; Jayme Jr., 2006).

Vale destacar que, uma visão detalhada da influência dos bancos e do sistema financeiro na economia, a partir de uma abordagem keynesiana, pode ser vista em Paula (2014). No primeiro capítulo, o autor descreve sobre os determinantes do comportamento dos bancos em uma economia monetária, a partir da abordagem da preferência pela liquidez. O segundo capítulo é relativo ao comportamento dos bancos e do crédito no ciclo minskiano. No terceiro capítulo discorre-se sobre financiamento da economia, funcionalidade do sistema financeiro e estruturas financeiras. Por fim, o autor fala a repeito do financiamento da inovação, buscando integrar uma perspectiva keynesiana, institucionalista e schumpeteriana.

Por fim, é importante mencionar a corrente formada por autores pós-keynesianos horizontalistas, segundo a qual a oferta de crédito é perfeitamente elástica. Logo, fixada a taxa de juros de mercado, os bancos comercias irão ofertar empréstimos de acordo com a demanda existente. Conforme Paula (2014), para esta corrente, os bancos não têm preferência pela liquidez, o que leva ao não racionamento de crédito pelos mesmos. Detalhes e discussões sobre a abordagem horizontalista podem ser consultados em Moore (1988), Costa (1993), Carvalho (1993) e Costa (1994).

\section{Resultados e discussões}

\subsection{Dados em painel polled}

A abordagem em dados em painel (ou dados longitudinais) permite combinar dados de séries temporais (time-series) com dados de corte transversal (cross-section) no mesmo modelo. Conforme Hill, Griffiths e Judge (2010), o método geral de dados em painel pode ser representado pela equação 1:

1 Alguns pontos deste item tomam como referência Griffiths, Hill e Judge (1993). Detalhes adicionais podem ser consultados em Wooldridge (2002) ou Greene (2000). 


$$
Y_{i t}=\beta_{1 i t}+\beta_{2 i t} X_{2 i t}+\beta_{3 i t} X_{3 i t}+\ldots+\beta_{k i t} X_{k i t}+\mu_{i t}
$$

em que $Y_{i t}$ é a variável dependente; $X_{i t}$, variáveis explicativas; $\beta_{1}$, intercepto; $\beta_{2} \ldots \beta_{k}$, coeficientes parciais de inclinação; $\mu_{i t}$, termo de perturbação estocástico; $i$, diferentes indivíduos; e, $t$, período de tempo considerado. Em forma matricial a equação 1 pode ser expressa por:

$$
\begin{aligned}
& {\left[\begin{array}{c}
Y_{i 1} \\
Y_{i 2} \\
\vdots \\
Y_{i T}
\end{array}\right]=\left[\begin{array}{ccccc}
1 & X_{1 i 1} & X_{2 i 1} & \cdots & X_{k i 1} \\
1 & X_{1 i 2} & X_{2 i 2} & \cdots & X_{k i 2} \\
\vdots & \vdots & \vdots & \cdots & \vdots \\
1 & X_{1 i T} & X_{2 i T} & \cdots & X_{k i T}
\end{array}\right]\left[\begin{array}{c}
\beta_{1 i t} \\
\beta_{2 i t} \\
\vdots \\
\beta_{k i t}
\end{array}\right]+\left[\begin{array}{c}
u_{i 1} \\
u_{i 2} \\
\vdots \\
u_{i t}
\end{array}\right]} \\
& Y=\quad X \quad \beta+\mathrm{u} \\
& \begin{array}{llll}
T \times 1 & K \times T & K \times 1 & T \times 1
\end{array}
\end{aligned}
$$

em que Y é o vetor coluna $T \times 1$ de observações sobre a variável dependente $Y$; $X$, matriz $K \times T$, representando as variáveis explicativas do modelo, sendo que a primeira coluna de 1 s expressa o termo de intercepto; $\beta$, vetor coluna $K \times 1$ dos parâmetros desconhecidos, $\beta_{1}, \beta_{2}, \ldots, \beta_{k} ; \mathrm{e}, \mu$, vetor coluna $T \times 1$ das $T$ perturbações $\mu$.

Nota-se, pela equação 2, que neste modelo geral os interceptos e os parâmetros podem diferir entre os indivíduos e de período para período de tempo. Dessa forma, o modelo não pode ser estimado em sua forma original, uma vez que existem mais parâmetros desconhecidos do que observações (Hill, Griffiths e Judge, 2010). Assim, hipóteses simplificadoras devem ser tomadas de forma a estimar os parâmetros desconhecidos. Dentre os modelos de estimação utilizados estão: pooled, efeitos fixos e efeitos aleatórios (ou modelo de componentes de erro).

Neste trabalho foi adotado o modelo agregado pooled, tomando como base o estudo de Cavalcante, Crocco e Jayme Jr. (2006). O modelo pode ser expresso por:

$$
Y_{i t}=\beta_{1}+\beta_{2} X_{2 i t}+\beta_{3} X_{3 i t}+\ldots+\beta_{k} X_{k i t}+\mu_{i t}
$$

ou em forma matricial: 


$$
\left[\begin{array}{c}
Y_{i 1} \\
Y_{i 2} \\
\vdots \\
Y_{i T}
\end{array}\right]=\left[\begin{array}{ccccc}
1 & X_{1 i 1} & X_{2 i 1} & \cdots & X_{k i 1} \\
1 & X_{1 i 2} & X_{2 i 2} & \cdots & X_{k i 2} \\
\vdots & \vdots & \vdots & \cdots & \vdots \\
1 & X_{1 i T} & X_{2 i T} & \cdots & X_{k i T}
\end{array}\right]\left[\begin{array}{c}
\beta_{1} \\
\beta_{2} \\
\vdots \\
\beta_{k}
\end{array}\right]+\left[\begin{array}{c}
u_{i 1} \\
u_{i 2} \\
\vdots \\
u_{i t}
\end{array}\right]
$$

O modelo com dados agrupados (pooled) pode ser estimado pelo método de MQO caso os pressupostos do modelo de regressão linear clássico sejam válidos, tais como: homocedasticidade e ausência de autocorrelação dos erros. Caso contrário, sugere-se a utilização do método de mínimos quadrados generalizados (MQG).

\subsection{Apresentação das variáveis}

As variáveis utilizadas nas estimativas econométricas estão descritas no quadro 1. Essas variáveis foram adotadas para atender ao objetivo geral da pesquisa e para estimação das regressões complementares (mais detalhes no item 4.2). A análise compreende o período de 2005 a $2010^{2}$ (dados anuais), considerando os 78 municípios do Espírito Santo, contemplando um total de 468 observações. Quando necessário, as séries foram deflacionadas pelo Índice de Preços ao Consumidor Amplo (IPCA) como no caso das variáveis: CRED, DEPvista, DEPprazo.

Os dados foram coletados no Banco Central do Brasil, por intermédio do programa de Estatística Bancária por Município, que inclui algumas contas do ativo e do passivo do balancete dos bancos comerciais e dos bancos múltiplos brasileiros por município com mais de três agências. Foi utilizado o saldo do mês de dezembro de cada ano para representar o saldo anual das operações ativas e passivas dos bancos. Entre as contas disponíveis foram adotadas: "operações de crédito", que reflete a parte do ativo dos bancos que possui menor liquidez, incluindo contas de financiamento e repasses governamentais para investimento. Já as contas "depósitos à vista”, “depósitos de poupança" e "depósitos a prazo" pertencem ao passivo do balanço dos bancos e proporcionam a percepção do comportamento do público em geral, tendo os bancos como intermediários.

A conta operação de crédito reflete as operações ativas realizadas pelos bancos com o intuito de aplicar seus recursos. Desta forma a conta operações de crédito irá representar no presente trabalho a proporção de investimento realizado pelos bancos em forma de oferta de crédito nos municípios do 
Espírito Santo. Representando a variável dependente da pesquisa, ou seja, a variável (Y) que será explicada pelas regressões estimadas.

QUADRO 1: VARIÁVEIS UTILIZADAS

\begin{tabular}{|c|c|c|c|c|}
\hline $\begin{array}{l}\text { VA R I A- } \\
\text { VEL DE- } \\
\text { PENDEN- } \\
\text { TE }\end{array}$ & DESCRIÇÃO & S $_{\text {GLA }}^{\text {I }}$ & $\left|\begin{array}{l}\text { UNIDADE } \\
\text { DE } \text { MEDI- } \\
\text { DA }\end{array}\right|$ & FONTE \\
\hline $\begin{array}{l}\text { Operações } \\
\text { de crédito }\end{array}$ & $\begin{array}{l}\text { Representa, em certo grau, } \\
\text { a atividade de captação de } \\
\text { recursos de agentes superavi- } \\
\text { tários e empréstimos a agentes } \\
\text { deficitários. }\end{array}$ & CRED & Milhões (R\$) & $\begin{array}{c}\text { E S T B A N } \\
(\mathrm{BACEN})\end{array}$ \\
\hline \begin{tabular}{|l|l|} 
V A R I A - \\
VEIS IN - \\
D E P E E N - \\
DENTES \\
\end{tabular} & DESCRIÇÃO & SIGLA & $\left|\begin{array}{l}\text { U N I D A D E } \\
\text { DE MEDIDA }\end{array}\right|$ & FONTE \\
\hline $\begin{array}{l}\text { Preferên- } \\
\text { cia pela li- } \\
\text { quidez dos } \\
\text { bancos }\end{array}$ & $\begin{array}{l}\text { Representa a decisão do siste- } \\
\text { ma bancário em alocar seus re- } \\
\text { cursos entre ativos de maior e } \\
\text { menor liquidez. Considerando } \\
\text { as contas operações de crédito } \\
\text { e depósitos a vista. }\end{array}$ & PLB & Índice & $\begin{array}{l}\text { Elaboração } \\
\text { d o a u tor } \\
\text { através dos } \\
\text { d a dos do } \\
\text { E S T B A N } \\
(\text { BACEN) }\end{array}$ \\
\hline $\begin{array}{l}\text { Preferência } \\
\text { pela liqui- } \\
\text { dez do pú- } \\
\text { blico }\end{array}$ & $\begin{array}{l}\text { Representa a decisão do pú- } \\
\text { blico em geral, de alocação de } \\
\text { seus recursos entre as contas: } \\
\text { depósito a vista, poupança e } \\
\text { depósito a prazo. }\end{array}$ & PLP & Índice & $\begin{array}{l}\text { Elaboração } \\
\text { d o a u to r } \\
\text { através dos } \\
\text { da dos do } \\
\text { E S T B A N } \\
\text { (BACEN) }\end{array}$ \\
\hline $\begin{array}{l}\text { Depósitos à } \\
\text { vista }\end{array}$ & $\begin{array}{l}\text { Operações bancárias passivas } \\
\text { de maior grau de liquidez para } \\
\text { o público tomador de crédito. }\end{array}$ & $\begin{array}{l}\text { D E - } \\
\text { Pvista }\end{array}$ & Milhões (R\$) & $\begin{array}{c}\text { E S T B A N } \\
(\mathrm{BACEN})\end{array}$ \\
\hline $\begin{array}{l}\text { Depósitos a } \\
\text { prazo }\end{array}$ & $\begin{array}{l}\text { Operações bancárias passivas } \\
\text { com maior prazo de maturida- } \\
\text { de para resgate. }\end{array}$ & $\mid \begin{array}{l}\text { D E P - } \\
\text { prazo }\end{array}$ & Milhões (R\$) & $\begin{array}{c}\text { E S T B A N } \\
(\mathrm{BACEN})\end{array}$ \\
\hline PIB & $\begin{array}{l}\text { Participação relativa do PIB } \\
\text { municipal no PIB estadual } \\
\text { segundo os municípios do Es- } \\
\text { pírito Santo. Segundo valores } \\
\text { de mercado. }\end{array}$ & PIB & $\%$ & IJSN \\
\hline $\begin{array}{l}\text { Dummy r } \\
\text { gional }\end{array}$ & $\begin{array}{l}\text { Tem o intuito de captar o grau } \\
\text { de desenvolvimento regional } \\
\text { do estado. Distinguindo a } \\
\text { microrregião Metropolitana } \\
\text { do Espírito Santo das demais } \\
\text { microrregiões. }\end{array}$ & DREG & & $\begin{array}{c}\text { Elaboração } \\
\text { do autor }\end{array}$ \\
\hline
\end{tabular}

Fonte: elaborado pelos autores. 
Dentre as operações passivas de captação de recursos do sistema bancário estão os depósitos à vista e os depósitos a prazo. Depósitos a prazo de forma simples, representam os depósitos efetuados em um determinado banco, com data prefixada para o seu resgate, sobre o qual o depositante recebe juros. Contrariamente, os depósitos à vista são um tipo de conta bancária onde o prazo de maturidade não é pré-fixado, ou seja, o público depositante pode resgatar o montante aplicado a qualquer momento, de forma mais específica, se trata de uma operação de maior liquidez para o público.

A partir das contas descritas foram construídos dois índices que pudessem refletir a preferência pela liquidez dos bancos e a preferência pela liquidez do público. Em relação à variável preferência pela liquidez do público, foi calculado um índice que reúne a proporção entre depósitos à vista e depósitos totais, sendo os depósitos à vista a soma dos depósitos à vista do setor privado mais depósitos à vista do governo. Por outro lado, os depósitos totais representaram a soma dos depósitos à vista mais depósitos de poupança e depósitos a prazo. Quanto maior o valor desse índice maior será a preferência pela liquidez do público, ou seja, maior será a decisão em ficar com seus ativos líquidos, dado o ambiente de incerteza,

$$
\text { PLP }=\frac{\text { depósitos à vista }}{\text { depósitos totais }}
$$

No que tange a preferência pela liquidez dos bancos, como a decisão dos bancos também varia de acordo com a relação institucional do sistema bancário, para verificar como os bancos alocam seus recursos entre ativos de maior ou menor liquidez, levando em conta o grau de desenvolvimento da região, foi calculado o índice PLB. As contas utilizadas para este fim foram os depósitos a vista de forma a representar a principal fonte de recursos dos bancos, e operações de crédito, que, em certo grau, representam a disposição bancária em emprestar dinheiro, ou tornar seus ativos menos líquidos. Consequentemente, quanto maior o valor deste índice maior será a preferência pela liquidez dos bancos,

$$
\text { PLB }=\frac{\text { depósitos à vista }}{\text { operações de crédito }}
$$

Por fim, ressalta-se que, com o intuito de captar os efeitos regionais sobre a oferta de crédito por grau de desenvolvimento, como sugere a bibliografia adotada, foi criada uma dummy regional (REGmetro) que representa a microrregião Metropolitana do Espírito Santo. A variável dummy assume o valor um no caso dos municípios que compõem a microrregião Metropolitana: Cariacica, Fundão, Guarapari, Serra, Viana, Vila Velha e Vitória; e, zero, para os demais municípios. 


\subsection{Análise das estimativas econométricas}

Este item contempla os principais resultados da análise empírica conduzida neste trabalho, seguindo a metodologia proposta por Cavalcante, Crocco e Jayme Jr. (2006). Nas estimativas as variáveis quantitativas foram transformadas em logaritmos. Os resultados das estimações estão contidos nas tabelas 1, 2, 3 e 4 e foram feitas pelo método de MQG (Cross-Section Weights) em pooled, com estimação do erro-padrão robusto por White Cross-Section ${ }^{3}$.

Conforme já mencionado, além da estimação da regressão que atende o objetivo principal deste trabalho, ou seja, como a PLB e PLP afetam o crédito, também se estimou regressões complementares. Uma das propostas destas regressões complementares se embasa no intuito de constatar o efeito do crescimento municipal sobre o crédito através da participação relativa do PIB municipal no PIB estadual. Além disso, pretendeu-se conferir de que forma os depósitos à vista e depósitos a prazo alteram a oferta de crédito capixaba. Desta forma, o modelo estimado admite que as operações de crédito sejam função da preferência pela liquidez dos bancos, preferência pela liquidez do público, depósito a prazo, depósitos à vista e participação relativa do PIB municipal no PIB estadual. Também foi estendido um modelo utilizando uma variável dummy regional.

As equações estimadas foram as seguintes:

$$
\begin{gathered}
\operatorname{LOG}\left(\text { CRED }_{i t}\right)=c+\beta_{1} L O G\left(P I B_{i t}\right)+u_{i t}, \\
L O G\left(C R E D_{i t}\right)=c+\beta_{1} L O G\left(\text { DEPvista }_{i t}\right)+\beta_{2} L O G\left(\text { DEPprazo }_{i t}\right)+u_{i t}, \\
L O G\left(C R E D_{i t}\right)=c+\beta_{1} L O G\left(P L B_{i t}\right)+\beta_{2} L O G\left(P L P_{i t}\right)+u_{i t}, \\
L O G\left(C R E D_{i t}\right)=c+\beta_{1} L O G\left(P L B_{i t}\right)+\beta_{2} L O G\left(P L P_{i t}\right)+\beta_{3} D R E G+u_{i t}
\end{gathered}
$$

De acordo com os resultados expostos na tabela 1, nota-se que a variável PIB é estatisticamente significativa ao nível de $1 \%$. Considerando os coeficientes estimados, uma variação na participação relativa do PIB municipal no PIB estadual proporciona um aumento de $1,01 \%$ no crédito. O sinal do coeficiente para a regressão com o PIB foi positivo, o que é condizente empiricamente, ou seja, uma região mais desenvolvida, que possui valores maiores para o PIB, apresenta variações positivas entre crédito e PIB.

3 Estas correções foram utilizadas com o objetivo de corrigir a heterocedasticidade e a autocorrelação. Para verificar a heterocedasticidade foi realizado o teste de White e para verificar a autocorrelação foi feito o teste de Breusch Godfrey. 
MONTE, E. Z.; VIANA, M. A. O impacto da preferência pela liquidez na disponibilidade de crédito dos municípios...

TABELA 1: OPERAÇÕES DE CRÉDITO E PIB NOS MUNICÍPIOS DO ESPÍRITO SANTO

\begin{tabular}{lcccc}
\hline VARIÁVEIS & COEFICIENTES & $\begin{array}{l}\text { E R R O - } \\
\text { PADRÃO }\end{array}$ & VALOR - T & P-VALOR \\
\hline C(Intercepto) & $4,583208^{* * * *}$ & 0,152946 & 2,996625 & 0 \\
LOG(PIB) & $1,016922^{* * *}$ & 0,006807 & 1,493926 & 0 \\
\hline$R^{2}=0,811792$ & $\bar{R}^{2}=0,811388$ & \\
\hline \multicolumn{7}{l}{ Valor P Estatística F=0,o0oooo } \\
\hline
\end{tabular}

Fonte: elaborado pelo autor a partir dos dados da pesquisa.

Nota: 1) $\left(^{* * *}\right.$ ) Significativo a 1\%; 2) Utilizou-se o método Mínimos Quadrados Generalizados (cross-section Weights), por pooling; 3) $\mathrm{L}$ = variável em logaritmo.

Os resultados da tabela $2^{4}$ referem-se aos depósitos à vista e a prazo tomando como variável dependente as operações de crédito. Ambas as variáveis apresentaram-se estatisticamente significativas ao nível de $1 \%$. Em relação ao volume de depósitos, percebe-se maior influência dos depósitos a prazo do que dos depósitos à vista, considerando que a variação de $1 \%$ nos depósitos a prazo provoca um aumento de $0,41 \%$ no crédito e uma variação de $1 \%$ nos depósitos à vista proporciona uma variação de $0,36 \%$. O aumento dos depósitos a prazo significa que mais recursos do passivo estão em posições menos líquidas e que, assim, há maiores opções de investimentos para os bancos, que podem aumentar o prazo dos recursos do seu ativo, ou seja, podem tornar-se menos líquidos e aumentar a disponibilidade de crédito.

TABELA 2: OPERAÇÕES DE CRÉDITO, DEPÓSITOS À VISTA E A PRAZO NOS MUNICÍPIOS DO ESPÍRITO SANTO

\begin{tabular}{lcccc}
\hline VARIÁVEIS & COEFICIENTES & E R R O & VALOR & P-VALOR \\
& & PADRÃO & - T & \\
\hline C(Intercepto) & $1,976784^{* * *}$ & 0,224376 & 8,810144 & 0 \\
LOG(DEPvista) & $0,361426^{* * *}$ & 0,072585 & 4,979378 & 0 \\
LOG(DEPprazo) & $0,411090^{* * *}$ & 0,051517 & 7,979659 & 0 \\
\hline$R^{2}=0,801051$ & & $\bar{R}^{2}=0,800192$ & \\
\hline \multicolumn{7}{l}{ Valor P Estatística F=0,000000 } \\
\hline
\end{tabular}

Fonte: elaborado pelo autor a partir dos dados da pesquisa.

Nota: 1) ${ }^{* * *}$ ) Significativo a 1\%; 2) Utilizou-se o método Mínimos Quadrados Generalizados (cross-section Weights), por pooling; 3) L = variável em logaritmo.

A conta depósitos à vista é positivamente relacionada ao volume de recursos

4 Esta equação tem como diferencial o emprego do método dados em painel não balanceado (unbalanced), como forma de desconsiderar a falta de dados para a conta depósitos a prazo para o município Ponto Belo nos anos 2005 e 2006. Desta forma, a regressão utilizou um total de 466 observações. 
emprestados, já que, independentemente do destino dos recursos, esses são computados como depósitos à vista para os agentes receptores de crédito. Ao receberem o crédito os agentes econômicos o disponibilizam, num primeiro momento, de forma mais líquida, ou seja, na conta de depósitos à vista.

Quanto à estimativa da tabela 3, esta toma como variáveis explicativas para operações de crédito a PLB e a PLP. Tanto a PLB quanto a PLP foram significativas estatisticamente ao nível de $1 \%$. Os índices de preferência pela liquidez apresentaram coeficientes negativos tanto para a PLB quanto para a PLP, ou seja, o aumento da preferência pela liquidez significa diminuição do crédito para o período. A variação de 1\% na preferência pela liquidez dos bancos leva a uma diminuição de 1,06\% no crédito. Já a variação de $1 \%$ na PLP leva a uma diminuição de 0,98\% no crédito. Em termos de PLB e PLP, o resultado mostrou-se condizente com o arcabouço teórico abordado anteriormente, porém, percebe-se maior influência da PLB do que da PLP, fato que pode ser explicado pelo período abordado compreender a fase de efeitos da crise internacional que alterou as expectativas dos bancos quanto ao cenário econômico nacional e estadual.

Este resultado ressalta a importância dos bancos na criação do crédito. $\mathrm{O}$ maior impacto apresentado pela variável PLB reflete a ação dos bancos como principal componente na criação do crédito. A PLB apresentou elasticidade significativamente maior do que a PLP, o que reforça a argumentação de que demanda por crédito possui pouca importância no volume de crédito ofertado em uma região. Isso se deve ao fato do crédito representar menor participação no lucro dos bancos brasileiros. Desta forma, a decisão de emprestar ou não seria pouco afetada pela variação na demanda por crédito, fato que seria indiretamente captado pela PLP.

TABELA 3: OPERAÇÕES DE CRÉDITO, PLB E PLP NOS MUNICÍPIOS DO ESPÍRITO SANTO

\begin{tabular}{lllll}
\hline VARIÁVEIS & COEFICIENTES & $\begin{array}{l}\text { E R R O } \\
\text { PADRÃO }\end{array}$ & VALOR - T & P-VALOR \\
\hline C(Intercepto) & $-4,438132^{* * *}$ & 0,092762 & $-4,784441$ & 0 \\
LOG(PLB) & $-1,067018^{* * *}$ & 0,053649 & $-1,988899$ & 0 \\
LOG(PLP) & $-0,980973^{* * *}$ & 0,069914 & $-1,403115$ & 0 \\
\hline$R^{2}=0,602452$ & $\bar{R}^{2}=0,60074$ & \\
\hline
\end{tabular}

Valor P Estatística $\mathrm{F}=0,000000$

Fonte: elaborado pelo autor a partir dos dados da pesquisa.

Nota: 1) $(* *$ ) Significativo a 1\%; 2) Utilizou-se o método Mínimos Quadrados Generalizados (cross-section Weights), por pooling; 3) $\mathrm{L}$ = variável em logaritmo.

A tabela 4 traz a relação dos índices de preferência pela liquidez com a dis- 
ponibilidade de crédito, diferenciando a Microrregião Metropolitana das demais microrregiões do Espírito Santo. Ressalta-se que todas as variáveis apresentaram significância estatística a 1\%. Os resultados reforçam o argumento teórico, uma vez que, o aumento de $1 \%$ na PLB causaria uma redução de $1,35 \%$ na oferta de crédito, da mesma forma que um aumento de $1 \%$ na PLP levaria a uma queda de $0,66 \%$ no crédito.

$\mathrm{O}$ fato dos índices de preferência pela liquidez se mostrarem importantes na disponibilidade de crédito é ainda mais forte regionalmente, dado o valor do coeficiente da variável dummy (3,043827). De fato, a preferência pela liquidez tende a ser maior em regiões menos desenvolvidas, corroborando também o argumento teórico de preferência pela liquidez distinta por região. Nos municípios considerados mais desenvolvidos no estado, a oferta de crédito é consideravelmente superior aos demais municípios capixabas, dado o menor grau de preferência pela liquidez do público e dos bancos.

TABELA 4: OPERAÇÕES DE CRÉDITO, PLB, PLP E DUMMY NOS MUNICÍPIOS DO ESPÍRITO SANTO

\begin{tabular}{lllll}
\hline VARIÁVEIS & COEFICIENTES & $\begin{array}{l}\text { E R R O } \\
\text { PADRÃO }\end{array}$ & VALOR - T & P-VALOR \\
\hline C(Intercepto) & $-4,514037^{* * * *}$ & 0,076362 & $-5,911396$ & 0 \\
LOG(PLB) & $-1,359149^{* * *}$ & 0,038008 & $-3,575946$ & 0 \\
LOG(PLP) & $-0,665477^{* * *}$ & 0,041912 & $-1,587807$ & 0 \\
DReg & $3,043827^{* * *}$ & 0,02314 & 1,315381 & 0 \\
\hline$R^{2}=0,740166$ & $\bar{R}^{2}=0,738486$ & \\
\hline Valor P Estatística F=0,000000 & & \\
\hline
\end{tabular}

Fonte: elaborado pelo autor a partir dos dados da pesquisa.

Nota: 1) ${ }^{* * *}$ ) Significativo a 1\%; 2) Utilizou-se o método Mínimos Quadrados Generalizados (cross-section Weights), por pooling; 3) L = variável em logaritmo.

\subsection{Ranking dos municípios em relação à algumas variá- veis do estudo}

Pode-se observar no quadro 2 que os municípios que recebem maior montante de crédito são justamente aqueles que apresentam maior PIB, ou seja, os dados comprovam a teoria de que os municípios mais desenvolvidos apresentam maior oferta de crédito. Além disso, regiões mais desenvolvidas apresentam maiores volumes de depósitos à vista e de depósitos a prazo, o que também se verifica na classificação dos municípios do Espírito Santo de acordo com a média dos anos de 2005-2010. Vale ressaltar que os municípios da microrre- 
gião Metropolitana destacam-se com grande volume de depósitos tanto à vista quanto a prazo. Na média dos anos de 2005 a 2010 a região Metropolitana apresentou cerca de $\mathrm{R} \$ 8,78$ milhões de crédito, $\mathrm{R} \$$ 7,57 milhões de depósitos à vista, $\mathrm{R} \$ 28,55$ milhões de depósitos a prazo.

Em relação à preferência pela liquidez, pode-se constatar que os municípios com maiores PLB e PLP são justamente os municípios com menor grau de desenvolvimento. A maioria dos municípios que compõem a classificação das variáveis PLB e PLP praticamente não aparece nas outras colunas de classificação referente às outras variáveis. Com isso, pode-se confirmar que os municípios menos desenvolvidos, com menor participação no PIB estadual e menor proporção de depósitos, apresentam maior grau de incerteza. Desta forma, tanto o público quanto os bancos tendem a manter seus ativos mais líquidos. Consequentemente, esses municípios recebem menor proporção de crédito dentro do estado, tendo em vista a maior incerteza regional e maior preferência pela liquidez.

O menor grau de PLP e PLB nos municípios da microrregião Metropolitana deve-se a maior proporção do PIB destes municípios, assim como localização geográfica litorânea que favorece o setor comercial e exportador destas localidades. Segundo estudo realizado por Leite e Magalhães (2012) o município da Serra, por exemplo, apresentou o maior índice de investimentos previstos entre o período de 2008 a 2013, demonstrando a ocorrência de padrões de concentração setorial nos investimentos realizados e previstos no estado. Do mesmo modo, nota-se a ocorrência de significativa concentração da população do estado em um número relativamente reduzido de cidades, estando estas cidades localizadas na microrregião Metropolitana da Grande Vitória (Leite; Magalhães, 2012). 


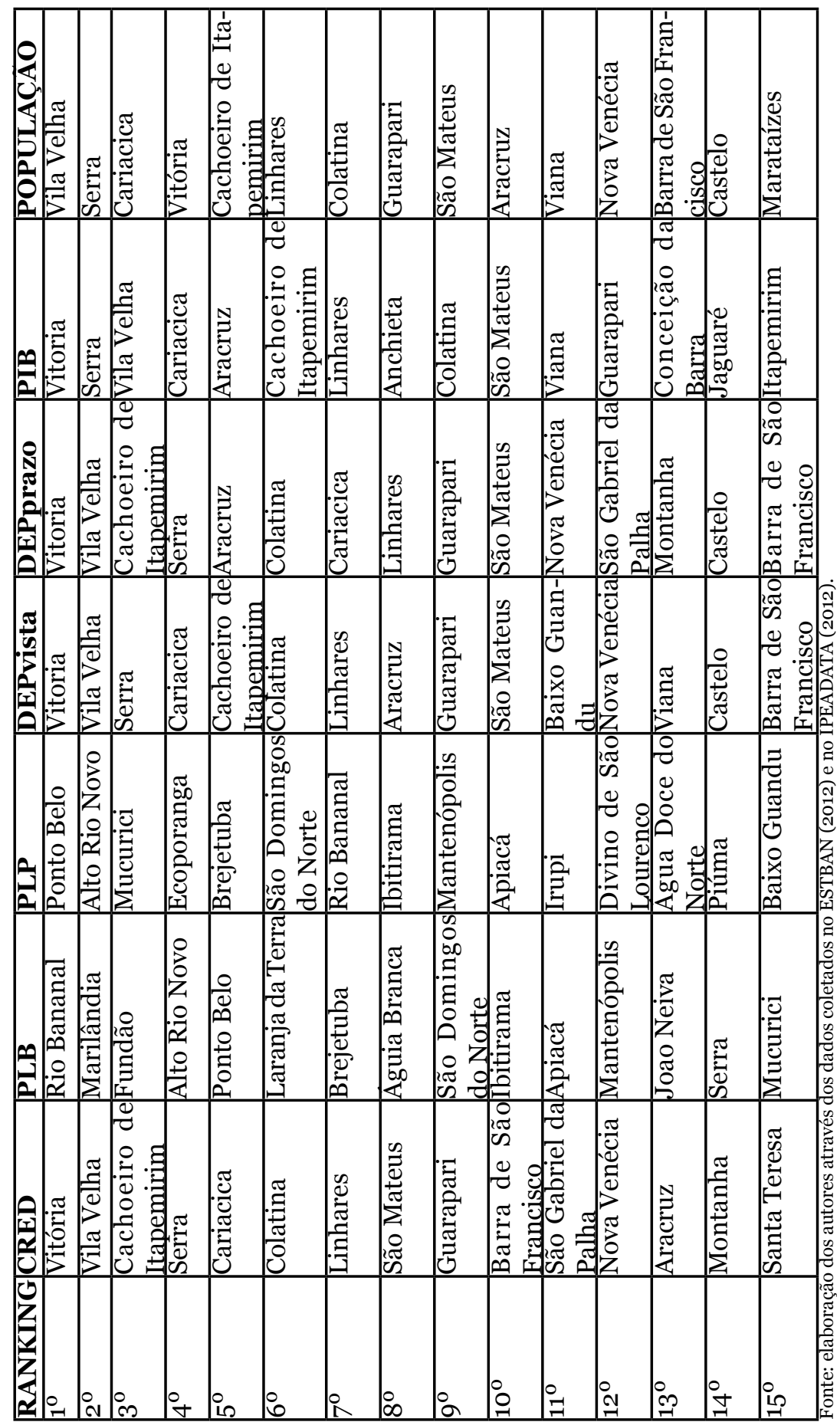




\section{Considerações Finais}

O presente estudo teve como objetivo principal verificar o impacto da preferência pela liquidez do público e dos bancos na oferta de crédito nos municípios do Espírito Santo. Também foram estimadas equações complementares com o intuito de constatar a influência das variáveis PIB, depósitos à vista, depósitos a prazo e de uma dummy regional na preferência pela liquidez. Os modelos estimados foram baseados no estudo de Cavalcante, Crocco e Jayme Jr. (2006), adotando-se método de dados em painel pooled como técnica econométrica.

No que se refere à regressão com PIB, os resultados demonstram que o aumento do PIB dos municípios aumenta a oferta de crédito nos mesmos. Esse resultado reforça a teoria de que municípios mais dinâmicos, ou seja, mais desenvolvidos, tendem a ter uma maior oferta de crédito. Em relação às contas do passivo dos bancos, verificou-se que o aumento dos depósitos à vista e a prazo elevou a oferta de crédito regional, sendo fortemente impactado pelos depósitos de maior prazo de maturidade.

Quando se considerou a preferência pela liquidez, os resultados revelaram que o aumento da PLB e da PLP reduz a oferta de crédito nos municípios do Espírito Santo. Em regiões com maior grau de incerteza econômica e menor grau de desenvolvimento, tanto o público quanto os bancos optam por manter seus ativos mais líquidos, ou seja, a região passa a dispor de menor quantidade de recursos para promover empréstimos ou financiamentos. Espera-se que, em um sistema de bancos, em que as operações de crédito sejam a principal fonte de lucratividade, a PLB e a PLP se relacionem inversamente com o volume de crédito.

No mais, os resultados da regressão, incluindo uma variável dummy regional, mostraram que as regiões mais desenvolvidas tendem a ter maior oferta de crédito. Ressalta-se que, na microrregião Metropolitana do Espírito Santo, estão concentrados os municípios com maior proporção de operações de crédito do estado (Cariacica, Serra, Vila Velha e Vitória).

Nesse contexto, a formulação de políticas públicas voltadas para maior disponibilidade de crédito para as regiões menos desenvolvidas é de fundamental importância, uma vez que o crescimento da oferta de crédito pode contribuir para o desenvolvimento destas regiões, proporcionando a interiorização do desenvolvimento, que muitas vezes é um dos principais objetivos dos governos. No caso específico do Espírito Santo, além das possíveis contribuições dos bancos públicos federais, o governo pode se utilizar dos bancos públicos, Banestes e BANDES.

Por fim, para trabalhos empíricos futuros sugere-se a aplicação de métodos econométricos mais robustos que os utilizados neste trabalho, como por 
exemplo, a metodologia de equações simultâneas, uma vez que as variáveis estudadas podem se relacionar de forma bilateral. Também, sugere-se um estudo que tente captar as diferenças em termos de oferta de crédito para todas das microrregiões capixabas, uma vez que neste trabalho a atenção foi voltada para a microrregião Metropolitana.

\section{Referências}

Caçador, S. B.; Monte, E. Z. (2011). "Crédito e crescimento econômico: o caso dos municípios do Espírito Santo”. In: Ix Encontro Nacional Da Associação Brasileira De Estudos Regionais E Urbanos, Natal. Anais... Natal: ABER.

Carvalho, F. C. (1993). "Sobre a endogenia da oferta de moeda: réplica ao Professor Nogueira da Costa”. Revista de Economia Política, 13(3): 114-121.

Carvalho, F. C. (1996). "Sobre a centralidade da teoria da preferência pela liquidez na macroeconomia pós-keynesiana”. Ensaios FEE 17 (2): 42-77.

Cavalcante, A.; Crocco, M.; Jayme Jr., F. G. (2006). "Preferência pela liquidez, sistema bancário e disponibilidade de crédito regional”. In: Crocco, M; Jayme Jr., F. G. (Orgs.). Moeda e território: uma interpretação da dinâmica brasileira. Belo Horizonte: Autêntica, pp. 295-315.

Cavalcante, A.; Crocco, M.; Jayme Jr., F. G. (2005). Preferência pela liquidez, sistema bancário e disponibilidade de crédito regional. Texto para Discussão. Belo Horizonte: Cedeplar.

Costa, F. N. (1993). “(Im)propriedades da moeda”. Revista de Economia Política, 13 (2): 61-75.

Costa, F. N. (1994). "Sobre o "horizontalismo" da oferta da moeda: tréplica ao Professor Cardim de Carvalho. Revista de Economia Política, 14 (1): 142-146.

Crocco, M.; Barra, C.; Cavalcanti, A.; Munhoz, V. C. V. (2003). "Desenvolvimento econômico, preferência pela liquidez e acesso bancário: um estudo de casos das mesorregiões de Minas Gerais”. Revista Análise Econômica 21 (40): 39-64.

Crocco, M.; Cavalcante, A.; Barra, C. (2002). "Polarização regional, sistema financeiro e preferência pela liquidez: uma abordagem pós-keynesiana”. In: XXX Encontro Nacional de Economia, 2002, Nova Friburgo. Anais... Nova Friburgo: ANPEC.

Crocco, M.; Cavalcante, A.; Barra, C. (2003). "Polarização regional, sistema financeiro e preferência pela liquidez: uma abordagem pós-keynesiana - novos conceitos”. In: VIII Encontro de Economia Política, 2003, Florianópolis. Anais... Florianópolis: SEP, 2003.

Dow, S. C. (1999). "The stages of banking development and the spatial evolution of financial systems". In: MARTIN, R. (ed.). Money and the Space Economy, London: Wiley, pp. 31-48.

Dow, S. C.; Fuentes, C. J. R. (2006).“Um “survey” da literatura de finanças regionais”. In: Crocco, M.; Jayme Jr., F. G. (Org.). Moeda e território: uma interpretação da dinâmica brasileira. Belo Horizonte: Autêntica, pp. 39-75. 
Fraga, J. S. (2009). "Uma abordagem pós-keynesiana de preferência pela liquidez: o sistema bancário e a concessão de crédito”. Revista de Administração, Contabilidade e Economia 8 (1): 155-174.

Freitas, M. C. P. (2009).“Os efeitos da crise global no Brasil: aversão ao risco e preferência pela liquidez no mercado de crédito”. Estudos avançados 23 (66): 125-145.

Freitas, A. P. G.; Paula, L. F. R. (2010). “Concentração regional do crédito e consolidação bancária no Brasil: uma análise pós-real”. Revista de Economia 11 (1): 97-123.

Greene, W. H. (1993). Econometrics analysis. 2. ed. New York: MacMillan. 802 p.

Griffiths, W. E.; Hill, R. C.; Judge, G. G. (1993). Learning and practicing econometrics. New York: John Wiley \& Sons Inc. 866 p.

Hill, C.; Griffiths, W; Judge, G. (2010). Econometria. 3. ed. São Paulo: Saraiva. 471p.

Keynes, J. M. (1936). The general theory of employment, interest and money. 1 ed. Londres: Macmillan.

Keynes, J. M. (1985). Teoria geral do emprego, do juro e da moeda. 2. ed. São Paulo: Nova Cultural.

Leite, M. L.; Magalhães, M. A. (2012). "Desigualdades intrasetoriais no Espirito Santo". Revista de Economia 38 (1): 55-92.

Moore, B. (1988). Horizontalists and verticalists: the macroeconomics of credit money. Cambridge: Cambridge University Press.

Nogueira, M.; Andrade, C. M. C.; Crocco, M.; Santos, F. (2009). "Rentabilidade das agências bancárias: um estudo para os municípios brasileiros”. In: Ii Encontro Internacional Da Associação Keynesiana Brasileira, 2009, Porto Alegre. Anais... Porto Alegre: AKB.

Nogueira, M.; Crocco, M.; Figueiredo, A. T. L. (2009). "Estratégias bancárias diferenciadas no território: o caso de Minas Gerais”. Texto Para Discussão. Belo Horizonte: Cedeplar, n. 345.

Oreiro, J. L. (2005). "Preferência pela liquidez, racionamento de crédito e concentração bancária uma nova Teoria pós-keynesiana da firma bancária”. Estudos Econômicos 35 (1): 101-131.

Paula, L. F. R. (2014). "Sistema financeiro, bancos e financiamento da economia: uma abordagem keynesiana”. 2. ed. Rio de Janeiro: Elsevier/Campus, 2014.

Romero, J. P.; Jayme Jr., F. G. (2009). "Sistema financeiro, inovação e desenvolvimento regional: um estudo sobre a relação entre preferência pela liquidez e inovação no Brasil”. In: Xiv Encontro Regional de Economia, Fortaleza. Anais eletrônicos... URL: [Online]: http://www.bnb.gov.br. Acesso em: 26 de agosto de 2013.

Silva, M. A. (2011). Impacto do Sistema Cooperativo de Crédito na Eficiência do Sistema Financeiro Nacional. Brasília: Banco Central do Brasil. (Trabalhos para discussão). URL [Online]: http://www.bcb.gov.br/pec/wps/port/td246.pdf>. Acesso em: 27 de agosto 2013.

Tada, G.; Araújo, E. (2011). "Crédito, moeda e desenvolvimento regional à luz da teoria pós-keynesiana da não-neutralidade da moeda”. In: Xiv Encontro Re- 
MONTE, E. Z.; VIANA, M. A. O impacto da preferência pela liquidez na disponibilidade de crédito dos municípios...

gional de Economia da Região Sul, 2011, Santa Catarina. Anais eletrônicos... URL: [Online]: http://www.anpecsul2011.ufsc.br/?go=artigos. Acesso em: o9 de setembro de 2013 .

Wooldridge, J. M. (2002). Econometric analysis of cross section and panel data. Cambridge, Mass: MIT Press. 
